\title{
Edinburgh Napier
}

UNIVERSITY

\section{SCHOOL OF LIFE, SPORT \& SOCIAL SCIENCES}

\author{
HONOURS PROJECT IN PSYCHOLOGY
}

2013-14

BA (Hons) Psychology

Amanda Diserholt

Death: Making Sense of the Nonsensical

Supervisor - Dr Calum Neill 


\section{Death: Making Sense of the Nonsensical}

\section{By}

Amanda Diserholt 


\section{ACKNOWLEDGMENTS}

First of all, I would like to sincerely thank my supervisor Dr Calum Neill, for his incredibly helpful support and encouragement throughout the whole project. His inspiring teaching motivated me to pursue an approach in Lacanian psychoanalysis. Secondly I would like to thank Julia, Kate and Erin* for kindly volunteering in this study as participants, whose willingness to share their personal experiences with a stranger online provided a rich basis for analysis. I would also like to thank my mother for her unequivocal emotional support, patience, and simply being there for me at every stage. Lastly I would like to thank Alexandra and Steve for their kindness and support and for undertaking the task of proofreading this work.

${ }^{*}$ Names have been modified to protect the identities of the participants. 


\section{ABSTRACT}

Modern Western society holds a perspective on death as being the opposite to life in an attempt to separate and exclude it from life, and thereby control it by overwriting it with knowledge and science. In contradistinction to this view, the current project explores the notion of death from the standpoint of Lacan's conceptualisation of a subject, a subject in opposition to the Cartesian conception dominating modern subjectivity. Lacan's theoretical framework offers a rich, in-depth account of the notion of death as it is structured through language. More precisely, human experiences are structured through the intertwining of the three registers constitutive of reality and subjectivity: the imaginary, the symbolic and the real. It is thus the main purpose of this project to trace the construction of death as it happens through the interaction of these three registers. Three volunteers participated in this study who wrote down two life-changing events. The guidelines stemming from the framework of a Lacanian Discourse Analysis (LDA) were applied to the narratives as a method for analysis. The analysis of these narratives revealed that the interaction of the three registers determines the position death gains in reality, that is, what sense it is given, which subsequently influences the experience of anxiety. The revealed relationships to death further elucidate three points. Firstly, as meaning and language are introduced in life, life and death become inextricably bound to each other. Secondly, as long as a symbol acts as a mediator between a subject and death, making sense of death becomes an impossibility; any attempt to put death into reason, finite knowledge or generalisations fails. Finally, death as standing both inside and outside our constructed reality sheds light on a necessary relationship to death that moulds an impossible, interdependent subject. 


\section{Table of Contents}

\section{ACKNOWLEDGMENTS}

(1) Introduction

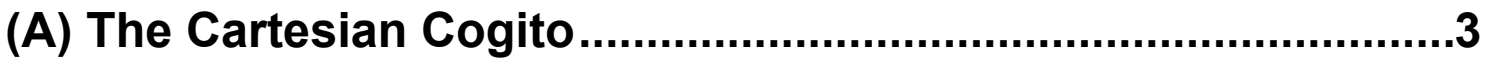

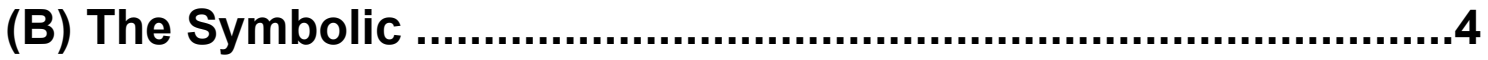

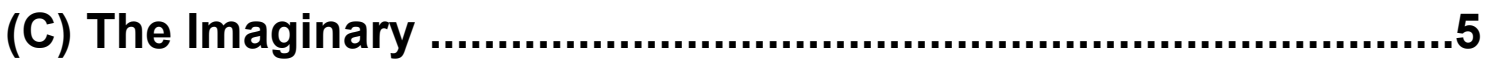

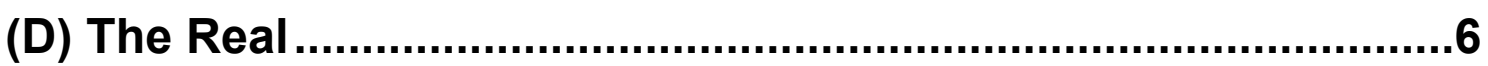

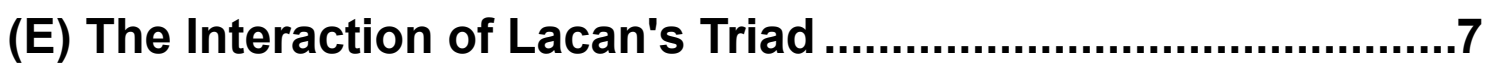

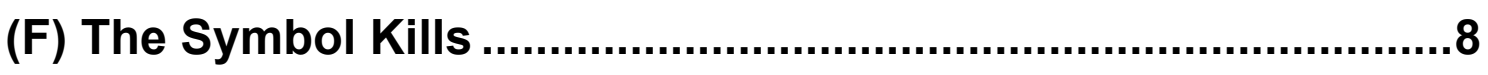

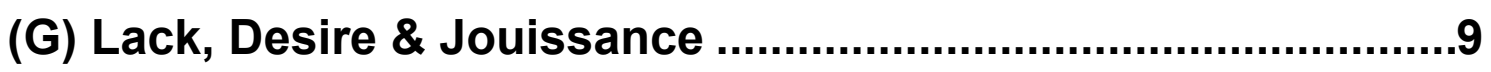

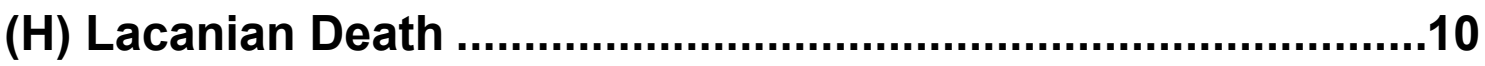

(I) Aim of the Project ..............................................................11

(2) Methodology .........................................................

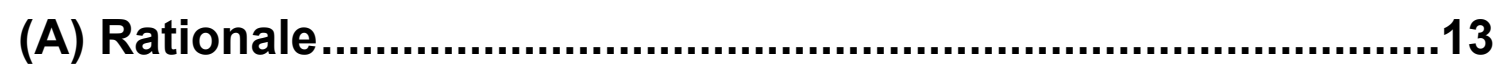

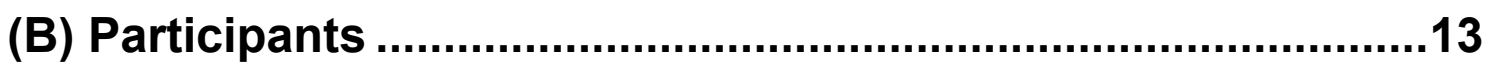

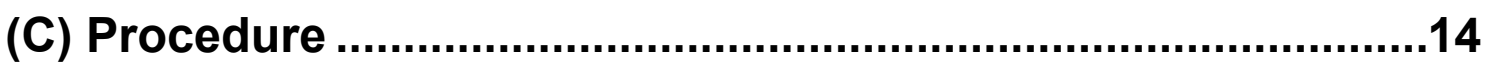

(D) Ethical Considerations ....................................................14

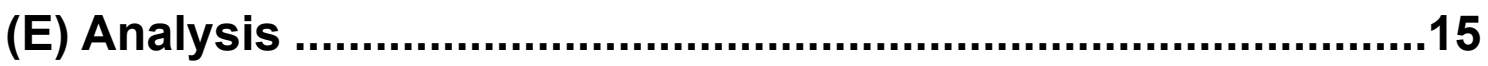

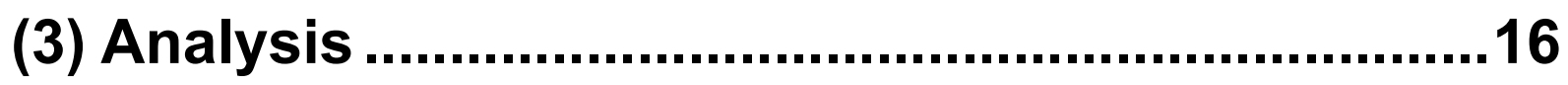

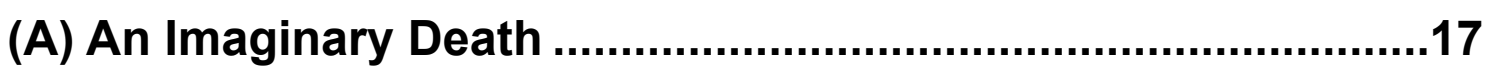

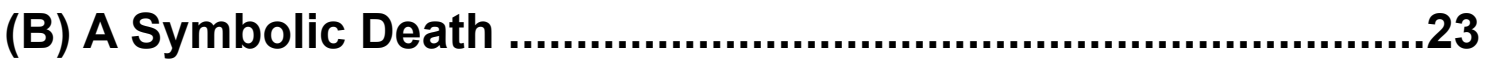

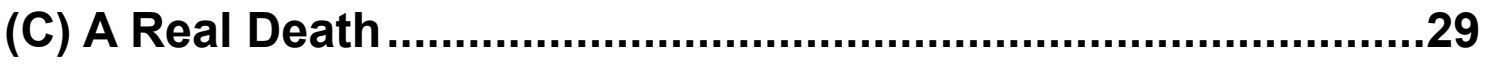

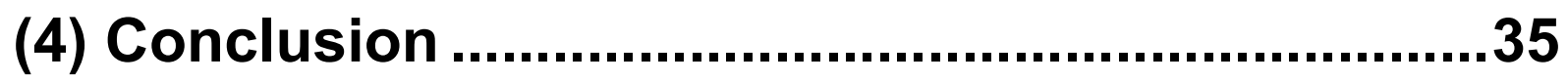

(5) References .....................................................38

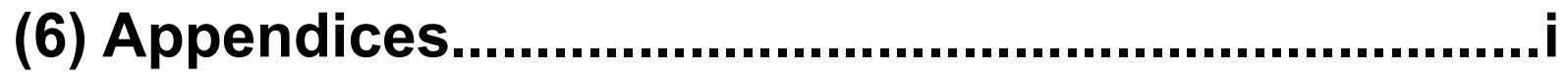

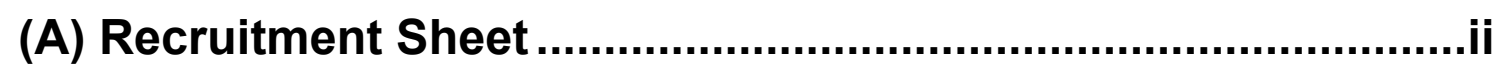

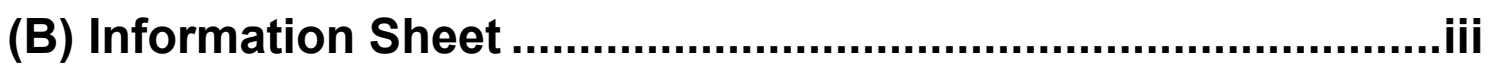

(C) Consent Form ......................................................................

(D) Instruction Sheet ............................................................

(E) Debriefing Sheet …...........................................................vi 


\section{(1) Introduction}

Around $300 \mathrm{BC}$, philosopher Epicurus claimed that death '...is nothing to us, seeing that when we exist death is not present and when death is present we do not exist' (Long \& Sedley, 1987: 150). It was in respect to this logic that Epicurus took an indifferent stance towards death, as he considered it irrelevant in life (Wrathall, 2005: 66). This line of thinking wherein death is seen as the opposite of life intends to separate the two and results in an attitude that ignores and denies the influence of death in our lives - an attitude permeating Western society. In the contemporary positivistic medical sciences, death only bears significance in relation to probabilities, and can be seen to be prevented by certain behaviour or newly promised technology (Loose, 2002: 138; Salecl, 2004: 46). Western contemporary society is also pervaded by a denial of death, emanating from the capitalistic lifestyle in the hope of fully enjoying ourselves (McGowan, 2004: passime). There is paramount evidence of the elimination of death from our lives in the belief that the uncertain can be certain and avoided as long as possible. Ironically, today's culture is witness to the rise of vampires, ghosts and the undead dead (zombies) in the popular fiction - modern society is an era of the uncanny in a time wherein these creatures are expected to be dead (Dolar, 2003: 7).

In fact, man can only be certain of is his own death and it is thus argued that the threat of death drives humans to construct meaning, direction, stability and a sense of control (Bendle, 2002: 223). This is recognised by existentialists who have, for a considerable amount of time, devoted large volumes of work to the study of death, where death is placed at the centre of the human being. In opposition to Epicurus, existentialist Heidegger argued that while we are not present at the time of death, we are present when death is a possibility, a fact that frames and gives significance to experiences as it defines human subjectivity (Wrathall, 2005: 67). Psychoanalysis, in line with this type of thinking, further acknowledges the incongruity between consciousness and unconsciousness seemingly underlying human behaviour. In 'Thoughts for the Times on War and Death', Freud (1957: 289) wrote:

It is indeed impossible to imagine our own death; and whenever we attempt to do so we can perceive that we are in fact still present as spectators. Hence, the psychoanalytic school could venture on the assertion that at bottom no one believes his own death, or, to put the same thing another way, that in the unconscious every one of us is convinced of his own immortality. 
Death is not only an integral condition of human life but also a complex notion, one that is necessary to explore in order to understand human behaviour and suffering. Further, as Freud recognised, imagining our death is an impossibility, but the actual act of imagining is possible, precisely because we have access to symbols through language that allows us to represent our own deaths symbolically. It is consciousness that enables spectating one's own death, which is why death is referred to as a singularity; it happens at an individual level (Bendle, 2002: 223). French psychoanalyst Jacques Lacan argued that once language and its accompanied meaning enters our life, 'death can be imagined, thought, ignored and feared' (Loose, 2002: 140). As Lacan's conceptualisations offer a rich, in-depth account of subjectivity and the presentational multiplicity of death as it is structured through language, it is the purpose of this project to explore the perception of death, and what kind of role it is given, through Lacan's psychoanalytic framework. This will be done through employing a Lacanian Discourse Analysis (LDA) on three volunteering participants' narratives in which they each share the stories of two of their lifealtering events. It is firstly necessary to delineate Lacanian subjectivity, what it is and what it is not, before returning to a Lacanian perspective on death.

\section{(A) The Cartesian Cogito}

Modern subjectivity is underpinned by the philosophical ideas stemming from Descartes and that have come to form the dominant conception of the self in Western society. This self is also embraced by the positivistic scientific paradigm and psychological science and is one in opposition to a Lacanian subject. Descartes' famous utterance 'I think therefore I $a m$ ' revolutionised subjectivity and induced a view of the self that is coterminous with the conscious mind - the so called Cartesian 'cogito'. By placing the thinking mind as the focal point of the human being, the cogito depicts an individual who is rational, self-conscious and self-determined and also one which could exist in isolation. However, Descartes himself found the argument that mere thinking can assure the existence of itself, i.e. thinking accounts for thinking, inadequate. In order to avoid this circular argument he had to rely upon an external source to confer his existence: God (Descartes, 2002/1641). Lacan does not fully dismiss Descartes' idea but instead highlights how his statement has depicted the underlying presence of the unconscious constitutive of a split of two minds (Fink, 1995: 40; Neill, 2011: 17). That is, Descartes, through his statement ' think therefore I am' has represented himself to himself through the double 'l's inherent in the sentence (Ibid.: 21). Descartes was thus right when he turned to something other than himself to 
uphold his existence, as an individual cannot exist in isolation but only against a background of something other than himself (Ibid.: 28). Specifically, language is this other place from which symbolisations of oneself are possible.

\section{(B) The Symbolic}

The possibility of a Lacanian subject to exist is through an intersection of three intertwined registers that constitute reality: the symbolic, the imaginary and the real (Chiesa, 2007: 142; Žižek, 2006: 8). A Lacanian subject is 'first and foremost the subject of language' (Neill, 2011: 17), referring to the subject of the symbolic, or in other words, the subject of the unconscious. The association between language and the unconscious can be understood from Lacan's famous saying that 'the unconscious is structured like a language' (Fink, 1995: 21). To explain this, the symbolic, referred to as the big Other in Lacan's terms, forms our beliefs, feelings and knowledge. It is not just inclusive of actual language, grammatical rules and signifying elements such as words, but is also inclusive of implicit and explicit rules and symbolic relations which support the social and cultural world in which we live (Salecl, 2000: 3; Žižek, 2006: 26). Lacan's theoretical ideas were inspired by Freud but also linguistics and structuralism, especially the ideas of LéviStrauss and Saussure (Homer, 2005: 34, Žižek, 2006: 4). Specifically, Lacan modified Saussure's concept of the signifier and the signified; the signifier referring to a word or sound pattern and the signified referring to that word's conceptual referent (Homer, 2005: 38). Instead of advocating for a direct relationship between these two, Lacan postulates a gap between them (Fink, 2004: 81). That is, a word can only be explained using other words as opposed to an external guarantor - a process referred to as the chain of signification, in which there is 'an incessant sliding of the signified under the signifier' (Lacan, 2002/2006: 503). Because of this, meaning is not inherent in words but rather insists between the sliding of the words. On the other hand, there are points de capiton, anchoring points that stop signification and temporarily fix meaning, preventing words from meaning too much or too little (Homer, 2005: 42; Neill, 2013: 337-8). Further, it was from Saussure and Lévi-Strauss that Lacan concluded that language governs us autonomously and unconsciously through the use of metaphors and metonymy: metaphors referring to word substitutions and metonymy referring to word contiguity (Homer, 2005: 44). Language then makes up the unconscious and consists of differential relation and equivalences 'without positive terms' (Saussure, 1974: 120 as cited in Parker, 2005a: 167) that operate automatically beyond our control and govern our experiences 
(Fink, 1995: 8). The subject of the unconscious then arises fleetingly in a representation between signifiers:

But this subject is what the signifier represents, and the latter cannot represent anything except to another signifier: to which the subject who listens is thus reduced (Lacan 2002/2006: 835).

The subject is thus an effect of language, which represents a radical otherness into which subjects cannot be fully incorporated, making language the discourse of the Other (Hook, 2008: 7). The subject of the unconscious, being the primary facet of Lacanian subjectivity, is a perpetually fleeting subject that adopts a position in relation to the unconscious signifying chain (Fink, 1995: 41). This is not the full picture of the Lacanian subject though as there is also the subject of consciousness, what Descartes alludes to in the representation inherent in the conclusion ' $/ \mathrm{am}$ ' (Neill, 2011: 25). This is the false sense of self, the ego belonging to the imaginary register that will now be outlined.

\section{(C) The Imaginary}

The imaginary is the second register that forms the Lacanian triad constitutive of reality and subjectivity. The imaginary stands at a subordinate level in relation to the symbolic and is the space of constructing meaning through ego identifications (Neill, 2011: 36; Neill, 2013: 339). In his most influential essay called 'The Mirror Stage' Lacan (2002/2006) describes the formation of the ego through the process of recognising oneself in the mirror. The mirror stage, equivalent to Freud's primary narcissism as it refers to the myth of Narcissus who falls in love with his own image reflection, represents the infant's encounter with its reflective counterpart usually at the age of 6-18 months (Homer, 2005: 24). The infant becomes fascinated with the idea of wholeness and mastery and thus identifies with the external image of oneself. The identification produces a sense of self, one that is autonomous and coherent and in opposition to its (his/her) body current state of fragmentation and lack of coordination - an image shifted from 'insufficiency to anticipation':

The mirror stage is a drama whose internal thrust is precipitated from insufficiency to anticipation - and, for the subject caught up in the lure of spatial identification, turns out fantasies that proceed from a fragmented image of the body...to the finally donned armour of an alienating identity that will mark his entire mental development with its rigid structure (Lacan, 2002/2006: 78). 
The reflective image, then, induces the emergence of a fantasy which supports the subject's quest to be perceived as whole. However, since the reflection with which one identifies and makes internal is something that is external, is an-other than himself, as well as incongruent with the body's current state, it is always a mis-recognition, ironically leading to the subject's alienation from himself (Chiesa, 2007: 18; Neill, 2011: 36). The alienation entails a gap between the subject and the image, hindering the subject from ever achieving a perfect self-identity, what Lacan refers to as lack of being (Chiesa, 2007: 18). The mis-identification, on the other hand, allows the individual to be constituted as a coherent ego that inaugurates a process of on-going identifications throughout life and through which one can form imaginary relationships with others. The imaginary is thus the place of love-hate relationships as it induces the condition of same and opposition, rivalry, love and narcissism, and also, in combination with the symbolic, allows a subject to (mis)construct a reality (Chiesa, 2007: 22; Fink, 1995: 84-5).

Returning to Lacanian subjectivity, the imaginary ego equated with the Cartesian subject is a false sense of being because it is 'mere conscious rationalisation' (Fink, 1995: 44). In this way, one can understand the incompleteness of the depicted cogito embraced by contemporary sciences and especially cognitive psychology. A Lacanian subject is neither this false sense of being and neither is it the subject of language (the Other) as these cannot fully represent the real subject. What is constitutive of Lacanian subjectivity is the split between these two mutually exclusive facets: the automatic function of language, the unconscious, and the ego as false sense of being (Fink, 1995: 45; Neill, 2011: 22). The emergence of the subject can only come about in relation to the Other and through the intercession of the symbolic, imaginary and real (Chiesa, 2007: 142).

\section{(D) The Real}

The third and last register in Lacan's triad is the realm of the real - one of Lacan's most challenging and multilayered concepts (Homer, 2005: 81). Lacan argued that Freud was concerned with the real which was the locus of repetition, impossibility and a resistance to interpretation as 'that which persists beyond the pleasure principle' (Eyers, 2012: 45, 15). In short, the real is that which lies outside the symbolic and imaginary, an impossibility due to its inability to be integrated into these two (Chiesa, 2007: 122). Accordingly, the real exists, a term Lacan borrowed from Heidegger meaning 'standing outside of as it is beyond our constructed reality/discourse. But it exists as something that can be named, while 
remaining unspeakable and ineffable (Fink, 1995: 25, 122). The real either precedes discourse or resists symbolisation, acting as a remainder in the latter (Fink, 1995: 25; Pavón Cuéllar, 2010: 39-40). Moreover, the real is associated with primordial flesh, 'the palpitation of...life substance' (Žižek, 2006: 66).

\section{(E) The Interaction of Lacan's Triad}

The three registers just outlined work in an inextricable way in which there is an interpenetration between the three of them (Eyers, 2012: passim). That is, the three are only conceivable together in an interconnected manner, which Lacan exemplifies with the illustration of the inextricable rings that form part of a Borromean knot. For example, the imaginary and the formation of the ego therein do not take place in complete solidarity but within a minimal, pre-existing symbolic network which is necessary for taking on meaning (Chiesa, 2007: 54; Eyers, 2012: 19), something Lacan acknowledges in Seminar II (Lacan, 1988: 257). The oppositional relationship between the symbolic and imaginary is further highlighted by Žižek (1989: 132):

The Imaginary level is governed by the pleasure principle, it is striving for a homeostatic balance, and the Symbolic order in its blind automatism is always troubling this homeostasis: it is 'beyond the pleasure principle'. When the human being is caught up in the signifier's network, this network has a mortifying effect on him; he becomes part of a strange automatic order disturbing his natural homeostatic balance.

There is a desire to ignore the constrains placed by the symbolic. Although, the symbolic is a necessity for creating distance between subject and object that makes co-existence possible (McGowan, 2004: 22). The role of the real in the symbolic and the imaginary is to stop them from coalescing (C. Neill, personal communication, March 19, 2014). That is, the real prevents and thus limits the symbolic from fully symbolising itself and the imaginary from entering into full hostility and aggression inherent in same/different opposition (Chiesa, 2007: 122). Simultaneously, the real overdetermines the two registers as it acts as their cause, the gravity around which representations circulate. The real is intrinsic in the imaginary as the fragmentation that causes the subject's imaginary identification with wholeness (Eyers, 2012: 17). Likewise, the real is the condition of the emergence of the symbolic subject because the real-of-the-symbolic is the materiality of language, what Lacan refers to as the letter, the signifier as it exists in isolation as opposed to in relation, the latter inducing sense and the possibility for meaning (Ibid.: 64, 38). The paradoxical nature of the real in both the imaginary and symbolic is that it 
threatens to disintegrate that which primarily it supports (Eyers, 2012: 34, 45). It is therefore clear that these three elements are only conceivable together and work in an inseparable manner. It is the aim of this project to trace the construction of death in relation to the interplay of the three registers, the symbolic, the imaginary and the real.

\section{(F) The Symbol Kills}

Death becomes conjoined with life insofar as language, accompanied by meaning, enters life through an annihilating effect which distinguishes a real from a constructed reality, and whose gap leads to the alienation constitutive of Lacanian subjectivity. This can be understood through the process of entering into the the symbolic: when a child becomes subjected to the Other, he/she gains a place as a subject however inevitably loses a part or her/himself in the process (Fink, 1995: 49): 'The subject, in a sense, is nothing but language while, at the same time, the subject is nothing because of language' (Neill, 2011: 23). Lacan depicts this process as the vel of alienation, that entails a choice between either/or of two parties that are mutually exclusive; either one chooses being or one chooses meaning inherent in the combination of the symbolic and imaginary. This 'choice' is forced, because choosing being inevitably entails a death of subjectivity and nonmeaning (Fink, 1995: 49-51; Neill, 2011: 23-4). To exemplify the latter, Lacan argues that death is inherent in the symbolic chain by paraphrasing Hegel: 'the symbol manifests itself first of all as the murder of the thing' (Lacan, 1977: 104). The symbol replaces our pure being in nature and is 'beingless', it represents nothing (Fink, 1995: 12; Neill, 2011: 45). Put differently, language implies a separation of the word from its representation; when a name for example is detached from the person supposedly representative in the word, it annihilates him/her insofar as the word becomes the absence of the (pure being of a) person and the two become mutually exclusive (Razinsky, 2013: 209). Hence, the real is what is killed by the symbol, while reality is what is constructed through discourse and carries meaning (Pavón Cuéllar, 2010: 10). Consequently, such action results in our alienation, a lack of being called manqué-á-être (Neill, 2011: 59). Alienation then entails an ontological status that is central to Lacan's conception of the subject, and pure being can only retrospectively be assumed to have been there before the symbol (Fink, 1995: 27). That is, language is made up of presences of absence which exclude the possibility of reaching a real, pre-discursive reality (Kirshner, 2005: 4). Death in the symbolic also becomes a presence of absence; the possibility of symbolising death makes us live in a sphere wherein life and death are inextricably bound. 


\section{(G) Lack, Desire \& Jouissance}

What further leads to an ontological lack is the process of separation, which is part of the process of socialisation through which one comes to occupy a place in society. To exist in society entails sacrificing something through a prohibition, something that Lévi-Strauss observed was inherent in every social order (McGowan, 2004: 11). The first prohibition and that which allows for the emergence of social coherence and culture is the incest taboo (Neill, 2011: 83). The most crucial aspect of the incest taboo that concedes this is the redirection of desire of the infant through breaking the hypothetical mother-child unity: instead of desiring the mother, the child's desire must aim at something/someone outside the family relations (McGowan, 2004: 12). The limitation hence acts as a second signifier which retrospectively signifies the loss of the mother-child unity (Fink, 1995: 56-7), subsequently signifying a loss of an unlimited, ultimate enjoyment that has come to be replaced by socially mediated enjoyment (Ibid.: 12). This ultimate enjoyment takes the guise of objet petit a (object a), previously coined the term das Ding, as the representative of the 'lost wholeness' retroactively assumed to have been there during the unity (Homer, 2005: 85; Neill, 2011: 49). Lacan refers to object a as the repressed 'hard impenetrable core', a lack, an absence around which the subject is constituted insofar as an articulation through language is an attempt to fill this absence (Homer, 2005: 84). Object a is then equivalent to the cause-of-desire as it inaugurates an insatiable, perpetual and fleeting desire, ever-seeking an object that is 'not it' (Neill, 2011: 40). Simultaneously acting as a lack, object a functions as a veil of alienation that allows the subject to ignore his division and gain a sense of wholeness in fantasy insofar as the object promises that unlimited enjoyment that was prohibited, what Lacan refers to as jouissance. The term jouissance for Lacan comes to denote a pleasure beyond the pleasure principle, an unbearable, intense pleasure in pain (Fink, 1995: 60; Žižek: 79). Even though jouissance is imaginary, it points to a facet of the real as it involves an impossible encounter with the real (Neill, 2011: 50) because it would result in the death of subjectivity. In brief, object a works on the three registers in the following way: it represents the subject's (and Other's) ontological lack on a symbolic level, it represents the object that would resolve the lack on an imaginary level, and lastly it acts as the core of the real which remains unrepresentable (ibid: 60). For all subjects, fantasy on an imaginary level is the answer to the confrontation with the external, unknown Other, in which the subject takes up a position in relation to object a and a subsequently orchestrates and stages jouissance (Fink, 1995; Neill, 2011: 60-61; Žižek, 2006: 48-52). Language thus marks a division: 'what is lost is being, what is 
gained is desire and access to language, but also a conscious awareness of death and an unconscious wish to master it' (Loose, 2002: 155).

\section{(H) Lacanian Death}

Lacan devotes a large part of seminar VII elucidating man's relationship to death through the use of the symbolic domain, specifically, a signifier:

How can man, that is to say a living being, have access to knowledge of the death instinct, to his own relationship to death? The answer is, by virtue of the signifier in its most radical form. It is in the signifier and insofar as the subject articulates a signifying chain that he comes up against the fact that he may disappear from the chain of what he is (Lacan, 1992: 295).

As has been seen hitherto, it is speech that allows the possibility of encountering the idea of death. While some argue that the thought of death is given a subordinate role in Lacan's work, others argue that death has an eminent position throughout. Dollimore (1998: 196 as cited in Bendle, 2002) stipulates that 'death is the lack which drives desire'. In line with this, Razinsky (2013: 219) highlights that object a is similar to death as it too acts as an unrepresentable, abyssal presence of absence around which our psychic presentations circulate. In this sense, death is inextricably linked with desire and enjoyment, a relationship that Loose argues lies at the heart of the experience of drug addicts (2002: 133-193).

How death instigates desire can be understood through Kojéve's reading of Hegel's master-slave dialectic, which Lacan takes inspiration from to form his thoughts on death. Hegel (1980) in his tale 'Lord and Bondsman' presents how the idea of self, i.e. consciousness and subjectivity, is constructed in and relied upon an interdependency. To explain this, the identity of both a master and its slave are dependent on a reciprocal recognition in order to be separated as two individuals; the slave gains his status as slave only through an acknowledgement from the master who recognises the other as slave, and vice versa. They are thus locked in a struggle for recognition with the possibility of distinguishing themselves as humans, both for themselves and for others (Kojéve, 1969: 9). It is argued by Hegel that what drives the slave into his position is a relationship with death, with what he calls 'the Absolute Master'. Specifically, it is the fear of the Absolute Master which is determinate; the confrontation with the ultimate negation, that leads to a dissolution of being, drives the slave into his position and motivates his workforce. 'In 
mortal terror man becomes aware of his reality, of the value that the simple fact of living has for him; only thus does he take account of the 'seriousness' of existence' (Kojéve, 1969: 24). In this way, death frames the master-slave dialectic, i.e. human subjectivity, as it is the terror of a renunciation of being that drives the struggle for recognition and desire (Bendle, 2002: 231); the threat of death propels us to construct a meaningful reality.

A subjectivity depicted in this way sheds light on Lacan's notion of 'extimacy': that which is most interior lies outside of the subject (Neill, 2011: 46-7). That is, there is not a neat separation between inside-outside, between subject-object; 'the Real is just as much inside as outside' (Evans, 1996: 58). The unconscious exists in an intersubjective setting instead of suppressed internally, which is radically opposed to the isolated individual of the Cartesian cogito. Death can be coterminous with the real as it is an encounter with finitude and mortality, an absence that is beyond our grasp (Razinsky, 2013: 219). However, this absence becomes such only by conceiving it within the constraints of a perceived inside, which is the paradoxical nature of the real (Eyers, 2012: 78). Therefore the real and death, in acknowledging their similar relationship to the symbolic, are equivalent with an indeterminacy as they are both internal and external to the symbolic, making them unsusceptible to any assimilation into reason and science (Bendle, 2002: 235). Respectively, death represents an absence from the standpoint of the symbolic and the imaginary, which means that any attempt to make sense of it escapes the construction of discourse. Thus, representations about death are ultimately misrepresentations (Critchley, 2004: 86) - making sense of death is an impossibility.

\section{(I) Aim of the Project}

The rationale behind this project, in terms of its focus on death, stems from the association between death and the real: both are a lack considered necessary for the rise of desire constitutive of subjectivity. Therefore, a relationship to lack is simultaneously a relationship to death and thereby, our incomprehensible mortality, alike our ontological division, is one which can be ignored in the phantasmic world. The aim of this project is to explore how one comes to construct the idea of death and what kind of sense it is given, through an exploration of the interplay between the three registers constitutive of Lacanian subjectivity: the imaginary, the symbolic and the real. This would shed light on the interaction between the three in coming to (mis-)construct a reality, and a subject, through the prism of death. Beforehand, it is not to be ignored that my own desire (or inability) to grasp the ungraspable is that which has fuelled the project but it is also something that has 
possibly coloured the project, especially considering my grandmother passed away in the midst of the process. A Lacanian Discourse Analysis, as a choice of methodology, is exactly one which acknowledges the reflexivity of the researcher and works with it in order to avoid the pitfalls that other approaches fall into (Neill, 2013: 334), as will be seen in the next section. 


\section{(2) Methodology}

\section{(A) Rationale}

My analysis is based on narratives written down by the participants of this study, who were asked to write down the stories around two of their life-changing events. The rationale behind this task stems from the conceptualisation of trauma as real from a Lacanian perspective. Trauma, for Lacan, is an encounter with the real, what he calls tuché: it is an irruption of the real into the orderly symbolic and imaginary world, making one realise there is something beyond the symbolic (Bendle, 2002: 232). There is a lack of representation which attempts to be covered over but fails as it remains unspeakable (Parker, 2005a: 176). A life-changing event entails an encounter with the real, and since the real and death have a similar relationship to the symbolic, a relationship to death can be inferred from this encounter. Further, by contextualising the task through a focus on how the participants (perceive they) live their lives today would reveal a position in relation to lack and a limit, as a change involves a shift in position in relation to the Other and object a (Fink, 1995: 62). This would allow the exploration of how the real, and hence death, is dealt with. For this reason, it was not necessary that the participants talk explicitly about death although this happened to be the case.

The participants were asked to write down two events in order to elicit enough data and to be able to discern any connection between them. It should be noted that the memories they chose to write down do not reflect an inner state or the events per se. Memories are not a direct encounter with the event but are reflections/thoughts induced afterwards as a way to make sense of an enigma (Žižek, 2006: 73), and as Lacan (1988: 191) states: 'trauma intervenes after the fact'. The process of writing down narratives further reconstructs these narratives as human consciousness is reflexive (Frosh, 2014: 48). Moreover, as it was one of the original purposes of this study to explore the cultural aspects of death, the participants were asked in what ways they perceived the events were shaped by culture. Finally, the events could have been either of a negative or positive nature, as both of these can have a significant impact.

\section{(B) Participants}

Three people in total agreed to participate in the study. The participants were recruited online and were friends or acquaintances of my friends. This method was chosen due to 
conveniency as well as avoiding analysing any close friends. None of the three participants were anyone I had met or were acquainted with. In order to protect their identifies, pseudo-names were given that are used throughout. There was no criteria for taking part but anyone could take part who were willing to share their life stories.

\section{(C) Procedure}

Recruiting participants and data collection took place online. A recruitment sheet (Appendix A) was sent to friends who in turn sent it to their friends/acquaintances on my behalf. This sheet contained the information necessary to take part. Due to the possibility of re-experiencing sensitive, traumatic events, the recruitment sheet explicitly stated the task of the study and that they should only participate if they felt comfortable with it. The sheet also contained my contact details and interested volunteers were instructed to email me should they wish to take part. Upon receiving their email I replied with instructions and with all the necessary documents. The first document included the three following sheets in one file: the Information Sheet (Appendix B), the Consent Form (Appendix C), and the Instruction Sheet (D). I instructed them to carefully read the Information Sheet which provided details of the procedure of the study. The information sheet further assured them that their data will be anonymous, that their data may be presented at a conference or published, and that they had the right to withdraw from the study at any stage without giving a reason, the latter of which I reinforced in the email. Next, they were instructed to sign the consent form electronically with their names. Lastly they were instructed to read through the debriefing sheet (Appendix E).

As the participants' narratives are of a highly personal nature from which their identity can be inferred, and in keeping with the promise of confidentiality, their full stories are not included as appendices to this project. I have still provided references to the quotes/ excerpts from the stories as to contextualise any chronological order between events: the first number refers to the participant, the letter refers to the life-changing event; $A$ to the first one and $B$ refers to the second, and finally the last number refers to the line number. For example, 1B/5 refers to participant one, life event two and line number five.

\section{(D) Ethical Considerations}

Prior to data collection, ethical approval was obtained from the Faculty of Health, Life and Social Sciences Research Committee at Edinburgh Napier University. 


\section{(E) Analysis}

A Lacanian Discourse Analysis (LDA) has been employed on the narratives as it fits very well with such a topic as death; the focus is on the form of a text and what it leaves out rather than describing its contents (Verhaeghe, 1995: 4). LDA was not developed by Lacan as his theory stems from a clinical perspective, but was developed based on Lacan's conceptual tools in order to arrive at a subsequently rich, in-depth analysis (Neill, 2013: 334). Psychoanalysis in itself offers a way to read texts, either written or oral as it captures the intersubjective nature of a subject (Young, 2014: 279; Žižek, 2006: 5).

LDA is underpinned by certain assumptions that are imperative to acknowledge. Firstly, the approach recognises the creative process involved in analysis since meaning does not exist independently in words, but insofar as there is a receiver who imagines a meaning. That is, we are all part of an inseparable discourse in which we construct meaning (Neill, 2013: 336-7). Secondly, there is no universe of discourse, meaning that language is not totalising or permanent, as something is always excluded and there is constantly more to say; meaning is fixed only temporarily and retrospectively (Ibid.: 337). Discourse analysis does not presuppose a reality that a text reflects, but the reality is the discourse itself (Pavón Cuéllar \& Parker, 2014: 2). That is, a text should not be approached as something to be understood in order to access a singular truth hidden within the 'internal world' of an individual person (Frosh, 2014: 24). Such an account would be, as Parker (2005b: 108) recognises: psychologisation, essentialisation and individualisation. Rather, the complexity of narratives needs to be acknowledged by looking at the subject in its wider structure. Lacanian psychoanalysis fits well with discourse theory as it refutes the individual-social division and recognises the subject's emergence in a socio-cultural context and further contributes with the importance of looking at the unspeakable (Frosh, Pheonix \& Pattman, 2003: passim). Failures, inconsistencies, variability and gaps show how the subject cannot be assimilated into a universal system but occupies a place in relation to the Other (Hook, 2008: 4, Pavón Cuéllar, 2014: 331-2). Thirdly, as discourse involves the interlinking of the three registers, the symbolic, imaginary and the real, the goal of LDA is to separate imaginary readings from the symbolic readings, the latter referring to the structure of the text by paying attention to order, choice of words, syntax, sentence structure, etc. (Neill, 2013: 341). Lastly, it is to be recognised that there is no meta-language. This refers to the impossibility of transcending language in order to arrive at a permanent, external knowledge that would confer a validity (Ibid.: 342). Having said this, the analysis that follows is only one possible interpretation amongst other, co-existing ones. 


\section{(3) Analysis}

The outline of the analysis is divided into three parts which respectively represents each participant. Coincidentally, the participants, Julia, Kate and Erin, are respectively focusing on three possible deaths, to the extent that the three can be distinct, situated within Lacan's triad: an imaginary death, a symbolic death and a real death. Specifically, the first participant, Julia, focuses on the perceived threat of her imaginary death. She tells the story of her mother having breast cancer and what kind of consequences this has had on her life. The second participant, Kate, is referring to another type of death which is possible in life: a symbolic death - the death of her subjectivity told in relation to the time that she and her friend got raped. Lastly, the third participant, Erin, is sharing her stories around the events of two real deaths: the death of her father and the death of a childhood friend with whom she was in love. The narratives from these participants will be explored in what follows as a way of shedding light on how the three Lacanian registers constitutive of subjectivity, the symbolic, the imaginary and the real (SIR) interact in coming to construct and shape the idea of death. Beforehand, it should be noted that the aim of the analysis is not to compare the narratives of the three participants in order to synthesise them into one unitary explanation of how death is dealt with. Rather, the analysis will hopefully reveal three different (im)possible relationships to death as conceivable responses to the incomprehensible. 


\section{(A) An Imaginary Death}

The imaginary, being the place of images, meaning and identification, is the place from which death can be given a sense of meaning and acts as the possibility of conceiving our own deaths. Lacan states that 'the ego is the closest and most accessible manifestation of death in the subject's life' (Lacan, 1988: 210) specifically because part of the (real) being is left out in mis-recognising oneself in the mirror. It is to be noted that an imaginary death does not refer to a death that is purely illusory and unimportant, but rather that death is accessed by imagining a point in the future wherein we, or others, do not exist. The first participant Julia centres her first life-changing event around the time that her mother got diagnosed with breast cancer. The narrative focuses upon explaining in what ways it has changed her life:

It has changed my life in different ways, the major one being that I'm fairly convinced that I will also get breast cancer. I'm also sure my mum will get it again despite her being in remission (1A/14-6).

Being convinced of having to live with breast cancer in the future stems from an imaginary identification with the mother; Julia considers herself similar to her mother through a (mis-)recognition, méconnaissance in Lacanian terms, of her ego in the reflection emanating from her mother. As Neill (2011: 126-7) points out, this process involves 'a misrecogntion of the other based on its similarity with one's own misrecognition of oneself. It is in this way the (mis-)identification grants her the possibility to stare at her own death in the mirror. Julia is thus dealing with the confrontation of her mother's potential real death in the future, which at this point is imaginary, and the (mis-)recognition induces the confrontation with her own imaginary death. Before exploring the aspect of the latter, it is necessary to turn to the pre-existing, interlinked roles of the symbolic and the real, which would consequently shed light on the influence of the interaction between the SIR on constructing an imaginary death.

The real in this story that is inherent in the confrontation could be seen to be the deteriorating body of Julia's mother. The traumatic quality around this event is discernible in the beginning of the narrative:

I didn't realise or understand what it meant when I first got told. Obviously I knew it was bad and she would need treatment and all that but I didn't 
really understand the implications it would have for everyone involved. It even took a while for the actual news itself to sink in, it was the middle of the night and I woke up and just burst into tears (1A/2-5).

By repeating the word 'understand' and also using the word 'realise' as seen from the above paragraph, implies that she is relying on these words precisely because the event cannot be understood and demands to be understood; something real has entered her life. This is evident in the disruption of common routines and reality: her brother fails school and there were heated arguments with her father 'because he [her father] didn't know how to cope with it, none of us did really (1A/10-1). The real, practical consequences in terms of treatment are understood while the meaning around the decaying body inherent in such diagnoses is obscured. Accordingly, the deteriorating body stands in the place of the Lacanian object $a$; the whole narrative text is focused on precisely the attempt to understand this place of absence: What does it mean for one's body to deteriorate?

The real in relation to the symbolic is attested to in Julia's story in its failure to provide knowledge and answers to the enigma of the human body. A subject's relationship to a symbolic representation is best illustrated through the Discourse of the Master - the fundamental structure of subjectivity as it underlies all other discourses (Pavón Cuéllar, 2010: 233) and for this reason contextualises Julia's relationship to the real and thus an imaginary death. For Julia, the identification with the master signifier guides what is possible to think about death, insofar as the master signifier inaugurates a chain of signifiers in form of a body of knowledge (Neill, 2013: 343). A master signifier is a sense giving signifier which holds meaning in place and authors laws and constructs ideology (Ibid.: 10, 16). In Julia's narrative, identification with breast cancer structures her knowledge about the illness: she is convinced she will herself get breast cancer and convinced the illness operates in a cause-and-effect manner, which is attested to when saying: 'I can only use certain types of contraception and narrows down what I can and can't use fairly quickly' (1A/17-8). This knowledge that is produced happens insofar as the '...enunciating workforce of the real subject works hard to interpret the master-signifier'... its purpose, intention and desire' (Pavón Cuéllar, 2010: 254). Similarly, Julia works hard to interpret the illness throughout her whole narrative: how does one get breast cancer, how can it be avoided, who does it happen to? These questions underlie and fuel the text as she talks about the consequences of her mother's diagnosis. The real's presence in the symbolic is discerned through a failure to symbolise the knowledge around breast cancer 
as the real acts to 'prevent the symbolic from fully symbolising itself' (Chiesa, 2007: 122), which produces a split subject (Pavón Cuéllar, 2010: 263). While Julia spends one third of the narrative explaining what she needs to do in order to avoid the possibility of getting breast cancer, the paradox is apparent in her saying in the end: 'Cancer can happen to the healthiest person alive no matter what culture they come from' (1A/26-7). This quote offers a glimpse into the insecure and unstable attachment to a symbolic representation. The identification fails and provides a divided, insecure subject: her mother 'rarely drank and she never smoked' (1A/26) but the real arrived anyway. The real, being that which has no consideration for the history of a person, has clearly marked its place, attesting to the impossibility of using any sort of reason, logic or knowledge in coming to understand questions regarding the real deteriorating body intrinsic to an illness.

Turning now to the symbolic-imaginary axis, while the master signifier comes to dominate the subject through slaving for the master, in turn he/she gains recognition from the Other and a subsequent feeling of mastery (Pavón Cuéllar, 2010: 239). Feelings of mastery and wholeness is that which is played out on an imaginary level wherein one can imagine the enjoyment that the symbolic prohibits, of transgressing the constraints that the symbolic imposes (McGowan, 2004: 18). Her ontological division is hidden under the illusion of being One' (Pavón Cuéllar, 2010: 240), under the signifier of breast cancer. This way one can come to understand the appeal for Julia to (mis)identify with her mother and breast cancer as it offers respite in an illusory belief that the real can be overcome. A possible reading is that the confrontation with the real results in Julia taking the lack of her mother to be her own lack, in a way transferring the illness onto herself so she can actively battle against (the possibility of getting) cancer:

I can only use certain types of contraception and narrows down what I can and can't use fairly quickly. Even very little things like l'm not supposed to drink diet drinks because of something that's in them (1A/17-9).

This type of focus on behaviour and especially avoidance of behaviour could be a way to attempt to control and manipulate the unknown, object $a$, in fantasy by endorsing the belief that if certain behaviours are avoided, one can escape the illness. The (mis)identification has therefore offered a sense of mastery, which shows itself in the text: '...if I managed to get through my mum having cancer I'm fairly sure I can cope with most other things' (1A/ 22-3). Moreover, as Julia associates breast cancer with a life-threatening disease in a 
cause-and-effect manner, i.e. cancer leads to death, this argument can extend to a desire to master death. What started off as her mother being diagnosed with breast cancer ultimately led to constructing an imaginary idea of (her) death:

So basically something I didn't even know existed that is in drinks and pills etc could potentially give me a life threatening disease, which just seems ridiculous to me $(1 \mathrm{~A} / 19-22)$.

This something she 'didn't even know existed' (1A/19), that is, something that barely exists has a large presence, could be referred to as death itself, as death represents a presence of absence - a logic which reflects a denial-of-death attitude. To elaborate on this, by focusing on behaviours that could and could not lead to breast cancer, alongside believing that a presence of small thing is 'ridiculous' (1A/22), implies a perceived limit being imposed on her. Specifically, a limit on the attainment of enjoyment, jouissance, since she cannot freely indulge in behaviours such as eating and drinking. In light of this, mortality for Julia is perceived as a failure to enjoy, in congruent with a desire to remove prohibitions in an illusory belief that it will provide wholeness and completion. Mortality is seen as 'ridiculous' - an error and a barrier to unlimited enjoyment. As McGowan (2004: 87) points out, the wish to transcend a limit is the wish to transcend the signifier of an illness as a way to escape lack and dissatisfaction. There is a desire to transcend the signifier of breast cancer; Julia is reducing the real to the imaginary by transferring her mother's lack onto herself, treating it as something that could be overcome by a focus on (imaginary) active behaviour and therefore believing death can be overcome. This is the work of the opposition between the symbolic and imaginary: the imaginary attempts to ignore the failure of symbolic knowledge.

On the contrary, the two last-mentioned quotes from Julia denote how the real disintegrates and disrupts the possibility of achieving full wholeness and mastery. In this case, the real is perceived in fantasy as 'something' present: 'something that's in them' and 'something' she didn't even know existed. The discourse here is indicative of the difficulty with naming the real, it is referred to as 'something', but the discourse is also indicative of how the real is perceived as a foreign intruder: it is an unknown and therefore alien-like thing coming from the outside that finds its way to the inside. This reflects a confrontation with her ontological alienation, with the fact that she is lacking. The irruption of the real into fantasy in this manner is similar to the notion of the lamella that Lacan uses to exemplify 
an undead-indestructible, libidinal object that resists symbolic support, a sort of undead real (Ibid.: 63): the lamella is something that insists and has a 'multiplicity of appearances that seem to enfold a central void' (Ibid.: 62). Likewise, breast cancer insists as there is a high chance of it coming back, evident when Julia says she is certain the illness will inflict upon her and it will return to her mother 'despite her being in remission' (1A/16). Žižek's (Ibid.: 64) explanation of Lacan's lamella clarifies its status:

...the lamella inhabits the intersection of the Imaginary and the Real: it stands for the Real in its most terrifying imaginary dimension, as the primordial abyss that swallows everything, dissolving all identities.

In this way, the imaginary clothing that the threat of breast cancer obtains, seeing that it attempts to represent a real decaying flesh, is a terrifying presence that takes no consideration of the history of human beings. The distinction between inside and outside becomes blurred, discernible in the discourse used: the real is perceived as a presence of an absence because 'even very little things' (1A/18) something that is barely there and cannot be seen, have big consequences and a big presence. That is, something that should be outside is inside which prevents a consistent, dialectical distinction between them. This is exactly the role of the real in both the imaginary and symbolic: the real 'threatens any consistent presentation of boundaries of the inside and the outside' (Eyers, 2012: 37). She comes up against the fragile boundaries of a constructed reality and subjectivity. Julia further describes this presence as ridiculous and was unaware of it which implies that it is a an unexpected presence. This notion of what is supposed to be an absence is actually a presence, in line with Lacan's notion of anxiety: what is most anxietyprovoking is that horrible object which is dissolves an identity. 'Anxiety emerges when at the place of the lack one encounters a certain object, which perturbs the fantasy frame through which the subject assessed reality', it is something that 'devours' the subject (Salecl, 2004: 24). It does so because an object appears and replaces the object of desire which results in a lack of the lack (Lacan, 2002b: 35). Lack, being that which is constitutive of a subjective existence, a lack of the lack would subsequently lead to a death of subjectivity (Žižek, 1991: 8). Similarly for Julia, the real of a decaying, ill and fragile body takes the phantasmic place of a random, alien-like, intruder, one that would devour her subjectivity and lead to a lack of a lack - her own death. What she thus comes up against is the groundless and feeble nature of existence through a confrontation with the real 
breakdown of the human body which ends in an imaginary confrontation with a deadly threat of the dissolution of a stable identity. 


\section{(B) A Symbolic Death}

The symbolic is not only that which primarily structures our relationship to death, but it entails a sort of death in itself as representations are detached from the real being and thus can function and govern autonomously. Lacan introduces the concept of a symbolic death, a second death, as one distinguished (also chronologically) from an actual, biological decay of a person, referred to as a first death (Chiesa, 2007: 148). In Seminar XII, Lacan (1992) illustrates man's relationship to a second death through a reading of Sophocles play 'Antigone'. The figure of Antigone is someone who goes beyond the limit of human life by defying the law of the city and is therefore excluded from the city's social domain and placed amongst the dead in a tomb. She becomes a 'living dead' - someone who is dead in life before her actual death. This space between life and death, wherein the symbolic death precedes an actual death, is referred to by Lacan as the zone betweentwo-deaths, following Sade's conceptualisation of this zone as an enduring fantasy of endless suffering (Žižek, 1989: 149). Based on these conceptualisations, a reading of the two life-changing narratives written by the second participant, Kate, suggests that she occupies a (non-)place between-two-deaths. While this is discernible through her first narrative, it is her second life-changing event that more clearly exemplifies the place between two deaths - an argument that will now be delineated through a focus on the interplay of the SIR.

In Kate's second life-altering event she tells the story around two rapes: she was raped by someone she considered to be her friend who at a later point raped another girl who was a friend of Kate's. Both of these rapes happened while the girls were drunk and unconscious for most of the time (2B/1-7). In understanding these events, it is crucial to acknowledge the interplay of the SIR in relation to the fundamental fantasy that led to her symbolically dead (non-)position. The fundamental fantasy is the most elementary coordinate that guides desire and is that which anchors the SIR, whose interlink allows the emergence of the subject (Chiesa, 2007: 142; Žižek, 2006: 59). In light of this, a second death is a 'momentary desubjectivizing permanence in the Real/void-of-the-symbolic' followed by a new symbolic re-inscription (ibid: 149). This re-inscription happens when a subject 'traverses the fantasy' in which the divided subject assumes responsibility for the cause of desire and gains a new position in regards to the Other and the Other's desire (Neill, 2011: 71), which is the goal of psychoanalysis. It can be seen that Kate has not yet taken on a new position as she considers herself dead in the eyes of the Other and stuck waiting for a new re-inscription. 
Starting with the real, it is discernible that the two rapes have a traumatic quality and that her rape has not yet been resolved, the latter which precipitates her (perceived) place within the zone between life and death wherein one is disconnected from a historical past and a future (Loose, 2002: 145). For Lacan, trauma can only be spoken about externally as it has not been integrated into the symbolic (Salecl, 2004: 131), evident for Kate when she continually refers to the rape of her friend, a second, external event that took place after hers. While she uses rape as a signifier as that which frames the two events, the explicit usage of this word only occurs in conjunction with her friend - the two rapes seem to have coalesced under the signifier rape as the main representative of the second rape that took place, and not her own. The narrative is thus mainly focused on the former event, and why it is so is clear in the following passage:

I feel so awful and so responsible for letting that man near her and not telling everyone that he was a big raper bastard. I keep hearing that I shouldn't feel guilty but I don't think l'll ever forgive myself (2B/30-2).

That Kate believes she will never forgive herself reflects the paramount responsibility felt towards what happened to her friend. Specifically, the task she perceived she failed with was to integrate the symbolic, a signifier, to her event as a way to prevent the second rape, discernible when she says: 'My life changed quietly when it happened to me' (2B/19), wherein quietly could be referring to no symbolisation, and that she 'didn't identify something off $(2 \mathrm{~B} / 36)$ when writing about why she failed to recognise him as a raper.

She refers to the historical and cultural differences, a chain of signification wherein the signified is sliding under the signifier, in coming to explain why he would rape her: he came from another culture, he was eccentric (2B/34-6), etc. This in opposition to a master signifier that would freeze the process and would render rape as rape regardless of the history of a person. Therefore, the failure to depend on the Other leads to finding herself accountable for the event(s) and one can come to understand her choice of words in the following excerpt:

I'm lucky that when something horrible happened to me the police were amazing, respectful and comforting, my case is being brought to trial and I haven't been stoned to death (2B/51-33; my emphasis).

Even though the police were respectful and did receive her case, mentioning death in conjunction with the Other, this case through the trial, reflects how she perceives herself in the eyes of society. The choice of words 'stoned to death' further reflects the 'choice' of her 
(non)position, as stoned to death refers to a capital punishment, and sometimes punishment for women who were raped in countries where the responsibility of such event falls on the victim. One of the important facets of the act of stoning to death is exactly this; while the woman is considered fully accountable for her (and other's) actions, there is no one accountable for the stoning of her death as it occurs collectively. Connecting this to Kate, having been unable to count on the Other, to use the symbolic, there is no one discernible on the other side that would legitimise any signifier and thus her existence. She potentially believes that the absence of this action lead to the rape of her friend, thereby perceiving herself as fully accountable for it and deserving a punishment and nonexistence. What Kate has come up against through this is the realisation of being dependent on something other for existence - the Other.

To elaborate on the last-mentioned claim, Kate's symbolic death has resulted in a confrontation with the insufficiency, or rather, self-sufficiency of existence and the 'radical unknowingness inherent in the symbolic order' (Neill, 2011: 43), the real, which sheds light on Lacan's notion that 'there is no Other of the Other' (Chiesa, 2007: 183):

The police questioning was concise and respectful, but so much of that will be completely undermined when we're questioned by lawyers $(2 \mathrm{~B} / 58-9)$.

Speaking about the trial, in which the lawyers and the police represent the societal aspect, Kate perceives a lack of acknowledgment of her experience in the eyes of society as she thinks it will be 'undermined', i.e. having no existence. Coming up against the lack in the Other in this way is similar to that traumatic process of coming to exist in language. Entering into the Other inevitably leads to the confrontation with the lack and desire of the Other in which one encounters the question 'Che Vuoi?' or 'What do you want?', a question perceived as directed to the Other from the subject in form of 'What does it want from me?' but also assumed as emanating from the Other to the subject in form of 'What do you desire?' (Neill, 2011: 42). The answer to this question lies in fantasy wherein one adopts a position as a divided subject in relation to the Other, a place where the trauma of lack of being, manqué-a-être, produced by an effect of language, is covered up (Ibid.: 61-2). For Kate, there is no Other to take a position in relation to in fantasy. This results in the realisation that the symbolic is inconsistent and not totalising; the nature of being is groundless and dependent on something other than oneself. Kate is dependent on society, in this case through the trial, to uphold the existence of her experience as being considered rape, and through this the existence of herself. Representation through a 
symbol is supposed to offer respite from the real as it distances the subject and object through a recognition from the Other (McGowan, 2004: 22). In contradistinction, Kate's (non-)position results in a lack of perceived distance between herself as a subject and the radical Otherness of the symbolic order. She consequently plunges into the 'unmediated jouissance of the real' (Ruti, 2012: 60), showing how a second death is not a death within the order of the symbolic, but involves the disintegration of that very system that acts as a support for existence (Bendle, 2002: 229); representations are nothing without a validation from somewhere else. It is the trauma of an unbearable jouissance in the absence of a protective fantasy that Kate comes up against.

The synergy between the symbolic and the imaginary elucidates that the real has not completely shattered and removed an imaginary world, as that would be deemed impossible. Instead, the real and its relationship to the symbolic disrupts and limits the imaginary, especially any stability and security that was felt therein: '...this guy, a friend, that I forgave and let into my house again, is actually a rapist and could assault two women' (2B/13-4) and she later goes on to say that: 'As a result l'm less forgiving of people' (2B/36-7). These quotes offer a glimpse into how the phantasmic idea of a friend crumbles down, that there is a limit to how much one can imagine to know. Not only this, but the existence of an imaginary ego is unbearable for Kate as it is seen as 'horrible':

It's a horrible feeling, and I hate knowing that I'm being talked about...I hate thinking that when people are being nice to me it's because of that [being a rape victim], and I haven't earned their respect or approval (2B/ 46-7,50).

Firstly, this quote marks the difference between a symbolic and an imaginary identification, between ego-ideal and ideal-ego, two concepts first coined by Freud. Lacan offers a clear difference between the two: ideal-ego is an imaginary identification that entails the idealised image, the way the subject wants others to perceive him/her (Žižek, 2006: 80). Ego-ideal, on the other hand, is a secondary and symbolic identification which has to do with the desired way one wants to be inscribed into the symbolic (Salecl, 2004: 145), it is the scrutiny of the Other; 'the agency whose gaze I try to impress with my ego image' (Žižek, 2006: 80). Secondly, the above quote, simultaneously as marking a distinction, elucidates their connection in that the ego-ideal moulds the ideal-ego (Chiesa, 2007: 23). There is a conflict between the two in Kate's narrative: something of her being, the ideal-ego, is symbolised and brought into existence by people talking about her. The 
imaginary ego's functions as an 'exit from the horror of undifferentiation, of fragmentation, and as a defence against being helplessly at the mercy of what emerges' (Blumenstein \& Ensslin, 2007: 3). The ego for Kate, by comparison, is clearly not acting as a bulwark but ironically acts as a horrible presence where there should be an absence. This brings us back to Lacan's concept of anxiety as being the presence of a horrible object that would devour the lack in a subject. The ego is a presence of that which would not acknowledge the current status of the ego-ideal, which is equivalent to lack and an absence, a nonexistence. Critchley (2008: 70) argues in a similar manner and in line with Levinas that what is dreadful is not the fear of death and nothingness, but rather 'being riveted to existence without exit'. Kate is in a way riveted to an existence that she wants to refute but remains an impossibility. Importantly, it is to be noted that a symbolic death does not entail a complete separation from the imaginary and the symbolic. Eyer's (2012: 28) explains the inextricableness of the two in that the ego-ideal is primarily an 'an imagined point of scrutiny'. Kate does have a symbolic existence, the police took her case seriously, and she does have an existence for others - but it is insofar as she refuses this existence that she imagines herself being dead through the gaze of the Other. Her ego-ideal is thus projected towards an imaginary Other.

What drives Kate into this position is responsibility towards her friend, attesting to the place between-two-deaths as one wherein there is a drive but no object of desire (Lacan, 1992: 249; Žižek, 1991: 16). Paradoxically, she needs a master signifier that would (temporarily) fix meaning and that would protect her from plunging into non-existence and non-meaning. Existing under the Other is equivalent to operating under a law, as 'that which allows the subject to maintain a subjective position within the safety and confines of the symbolic order' (Neill, 2011: 89). It is thus no coincidence that Kate alludes to death in relation to the Other, police and lawyers being the epitome of law. Alternatively, being 'stoned to death' is exactly a way to uphold the law as it is inflicted in order to 'correct' the disruption of the law perceived to be caused by the women. In this way, instead of desiring death and non-being inherent in such punishment, Kate, through mentioning such action can be seen to be pleading for laws and an-Other to count on as a result of the confrontation with the trauma and real of rape. The capital punishment can be translated into a desire to provide a meaning and coherent reality in an attempt to inflict laws where they are not perceived to exist, and a desire for the new re-inscription of the fundamental fantasy. The latter is seen in her last sentence that offers the quintessential place betweentwo-deaths: 
Waiting for the trial feels like just clinging on waiting for a big loud event that will be as traumatic as the rest, with press and all the scary things when I just want to be able to move on (2B/62-4; my emphasis).

That she ended like this alludes to the transitory, temporary place of between-two-deaths, which is associated with waiting rooms wherein one waits for the reinstitution of the ego as an object (Blumenstein \& Ensslin, 2007: 9-10). Kate is waiting, and desiring the emergence of a new fantasy that will provide an answer to the enigma (and inconsistency) of the Other and cover up her experienced lack. That is, she is stuck in a deadlock between a drive for responsibility but a desire for a symbolic place, split between being fully responsible for oneself while simultaneously having no (symbolic) place from which to take action - an unbearable, anxiety-producing situation. Lastly, Kate's narrative also elucidates the driving force of nothingness, of lack of being, which is why she resembles the position of the slave in Hegel's master-slave dialectic: the threat of death motivates desire and the workforce for a signifier; she wants 'to be able to move on' (2B/64). Finally, her story illustrates that there can be no acknowledgment of existence if one does not acknowledge the acknowledgment emanating from the other place - existence is interdependent with the Other. 


\section{(C) A Real Death}

Death in the register of the real refers to an actual biological death of a person, what Lacan refers to as the first death (Žižek, 1989: 150). The last and third participant, Erin, comes to have a relationship to two real deaths as she writes about losing her father to cancer in her first life-changing event, and losing her childhood friend with whom she was in love in a motorcycle accident in the second life-changing event. The focus of the analysis will be through a mergence of the two events that took place as the they happened only four months apart and thus seem to be inextricably linked. In what follows, I will analyse the interconnected role of the SIR, through a focus on object a's function in these, in coming to structure (mis-)representations of death.

Firstly, an attention to the real elucidates that the two deaths entail an unrepresentative, unspeakable traumatic nuance that occupy the place of object a. Erin, upon explaining how closely in time her father and her friend died, wrote: 'No words can describe what I was feeling' (3B/25-6) and that her father's death 'was and will always be the biggest shock of my [her] life' (3A/10), which point to a real trauma. The representations of the text are therefore circulating around and trying to understand the two deaths that occurred, as they act as the impenetrable, repressed core. Secondly, turning to the interplay of the symbolic and the real, the death of Erin's father entailed real consequences as it meant a symbolic change in that it altered her ego-ideal; how she views herself through the eyes of society. When he died she had to provide for herself, she had to 'serve others when I was used to the opposite' (3A/20). Further, this new position comes with strong feelings as she is ashamed for having 'dropped a social class' (3A/24). The event is therefore associated with two types of losses: that of her father and that of her symbolic position.

After my father no one else cares about me like that. No one loves me that much. The infinite bank is no more. I have to work to have money, it was not like that before $(3 \mathrm{~A} / 12-4)$.

The 'infinite bank' has twofold associations when it is placed in between explaining her father's love followed by explaining how she has to provide for herself. It can be seen that the 'bank' refers both to the unconditional love, the jouissance perceived to have been received from her father, as well as real money that was infinitely provided for her, that also provided her with a symbolic legitimisation in the gaze of the Other. 
That this new position is 'exhausting' and that she 'hates it' (3A/14-5) denotes that the trauma involves more than interpreting the real around their actual deaths. It involves interpreting the real consequences: why was she left to a position that she hates? It was an unexpected change imposed on her that demands answers. The death of her friend on top of this drives her to question her life:

He died four month after my father. No words can describe what I was feeling, The two heroes of my life left me one after the other. How can you continue living after that? (3B/26-7).

Placing the above-mentioned question immediately after describing how traumatic the events were denotes that this question is one at the core of her being. Moreover, that it comes in a form of a question is interpreted as an appeal to the Other. The question could then have twofold readings, the first one being that it is addressed to herself emanating from the Other in form of 'How can I continue living in my new social position?' and secondly it is addressed to the Other in form of 'How can you, the Other, continue existing after all this?'. The latter can also be translated into 'How can the world I find myself in bear any meaning?', as the symbolic in conjunction with the imaginary is that which gives meaning. This type of questioning is in line with the ontological structure of the hysteric which relentlessly questions his/her symbolic title, questioning the desire of the Other through asking: 'Why am I what you're saying that I am?' (Žižek, 2006: 35). The hysteric questions what kind of object one is in the eyes of the Other through demanding that the master show his knowledge, as the desire of the Other is what is most anxiety-provoking (Fink, 1995: 133; Salecl, 2004: 77). It can then be seen that through imposing the question to the Other, Erin demands answers as to why the two loved ones were taken away from her unexpectedly that led to a new symbolic status, precisely because she does not hold the answers herself. The latter is seen in the repetitive usage of the word 'survival', writing that she is 'a fighter' $(3 \mathrm{~A} / 18)$ who has to push herself 'in order to survive' $(3 \mathrm{~A} / 19)$ - she is struggling to live. The aforementioned attests to death's place in object a as that which inaugurates the process of signification and a desire to reach what has been lost. $A$ plausible explanation for turning to the Other is now necessary through the interplay of the symbolic and the real, before focusing on the imaginary contents of death.

Turning more closely to object a on a symbolic level, the ontological lack evident in the above analysis is caused by object a, the real deaths. However, and especially when it 
comes to the death of her friend, the object cause of desire is mistaken to be in the symbolic, in line with Žižek's (2006: 67) observation that the object of desire (the symbol) is (mis)taken to be the object cause of desire (in this case death). In exploring this statement, the real limits the symbolic insofar as words can no longer be received for the other who is gone. Like Kate, the second participant, there has been a failure to use symbolism, but in this case a failure before the event which has resulted in the perception of a forever lost and unattainable love. To explain this, an attention to the repetitive use of the word 'talking' is useful. Repetition and gaps in discourse indicate a real emptiness behind the symbolic (Pavón Cuéllar, 2010: 97). Erin is constantly using the word 'talking' to try to cover up the real when describing the relationship between her and her childhood friend, as opposed to 'meeting up' for example, which shows the paramount importance Erin places on the activity of speech. The importance of this becomes clear in her quote: ' never said I love you' (3B/33-4). Speech is that which symbolises and thus brings things into existence: 'language presents itself as a sign that represents, communicates, signals, facilitates something for someone' (Borch-Jacobsen, 1991: 137). It only does so because it is received and imagined to exist by someone else. Her love to him was never brought into existence because it had no receiver, not even herself: 'I 'loved' him too but never admitted it-not even to myself (3B/3-4). In line with Hegel's master-slave dialectic wherein a master receives his position only through acknowledgement from the slave, likewise, the relationship and the love between Erin and her friend never truly existed in the eyes of the Other, and therefore, Erin perceives it as never existing at all.

This corroborates one of Lacan's main theses that underpins discourse, that symbols and words only mean something in an intersubjective setting as meaning is not inherent independently in words (Neill, 2013: 336). Additionally, McGowan (2004: 21) emphasises that the importance of speech is not in conversation but conservation, the reason being that speech allows us to 'extend enjoyment' precisely because symbolisation means we can enjoy it in its absence after an object has disappeared. The importance of speech thus becomes evident for Erin: the symbol is perceived to hold that which would have allowed her to extend enjoyment and enjoy it in the absence of her friend's death. This process resembles that of symbolic castration, which highlights how prohibition and desire work in a Lacanian context. Namely, the movement of desire is inaugurated by a prohibition that leads the subject to retroactively perceive an enjoyment as beyond that limit and beyond the symbolic within which the constraints are imposed. Therefore the limit causes desire for something more that one cannot have. For Erin, the symbol gains a desirable status 
retrospectively because it is unattainable. Her scenario thus acts as the quintessential of Lacan's notion of the contradictory and elusive nature of desire, confirmed in the imaginary readings of the narratives. Erin repetitively uses the word 'perfect' throughout and also in conjunction with describing the two, especially her friend, and she also refers to the two as 'heroes' $(3 \mathrm{~B} / 26)$ - the two deaths are seen to be losses of people who in fantasy are elevated to the status of that impossible jouissance that would lead to wholeness and completion. As Ragland (1995: 100) puts it: 'In our attempts to keep the ground from shifting, we idealize our objects, clothe people and thoughts with the ideological garments of the good, the true, and the beautiful'.

A further insight into imaginary readings, but most importantly the intertwining of the symbolic and imaginary, is necessary in order to understand what precipitates her perception of death. A refuge in the symbolic is most evident in the following passage:

So. What I learned from this is that you have to speak up. Act immediately. Say what you want to say. Now. Do not keep it to yourself. Share it. Make the other person happy (or sad or angry). Speak up. Otherwise you will be regretting it for the rest of your life and the guilt and regret that will haunt you is not worth it (3B/ 30-3; my emphasis).

This appeal to the literal speech of the Other in the form of 'speak up' alludes again to the desire of the hysterics who fantasies scenarios in which the Other is perceived to be in possession of the sublime object (Salecl, 2004: 75). Not only is this evident in the use of repetition but also by the use of saying it 'now' and 'immediately' - as if the Other has that jouissance that knows no limits. Immediate access to jouissance is exactly the quest to eliminate the distance between desire and the object of desire. In this way, a turn to the symbolic can be a wish to rectify what has been lost, a demand to retrieve the perceived lost jouissance as a way to escape the trauma that the real entailed - it is seen as a protection against the lack inherent in trauma. Additionally, the short sentences used above can be a way to demand meaning and thus life, as a punctuation is that which secures meaning temporarily (Parker, 2005a: 170). 'Speak up' can then be translated into 'Make that jouissance exist that you were supposed to provide!' and 'Provide me with a meaningful life!'. However, it is only insofar as she imagines this to be the case that it is a turn to an imagined symbolic. The process of using an imagined symbolic in this manner can be seen an attempt to overwrite the real with the imaginary and the symbolic. Not only 
is she psychically attempting to escape, but also physically: 'I survived but that was the reason I left home and went to another country. Not to be close to all that' (3B/27-9). The irony is that an attempt to escape the real makes the real more intrusive and more present than ever:

Otherwise you will be regretting it for the rest of your life and the guilt and regret that will haunt you is not worth it (3B/32-3).

This discourse, being addressed towards others in form of advice, is given precisely because she is living with regret and guilt that haunt her. It is again in line with the concept of anxiety from a Lacanian perspective; that the real escapes as a remainder that acts as a reminder and a presence of the unsymbolised trauma of the two events - it haunts her incessantly and is that which, if encountered without the protective illusion that fantasy provides, would result in the death of her subjectivity. Because of this, she constructs death in fantasy as that which caused her guilt and regret. That is, an attempt to deny and escape the real constructs death as something more frightening, and is seen as an error and a barrier to the impossible enjoyment. This is also seen in terms of the death of her father:

He was supposed to be superman, he was supposed to be immortal, how can he be in this bed needing me to give him water? (3A/6-7).

Here is another question imposed as a demand to understand the real, especially to understand the real of a deteriorating body. She emphasises that she is the one to give him water, which denotes a dependency but one that is inverse to what it is supposed to be - it is dependency that death entails that is unfathomable. An illness that ultimately leads to the decomposition of a body has resulted in a fragile state wherein one is dependent upon basic items, a water and a bed, in order to hang onto life. It is an unexpected turn in the opposite direction to immortality; death shatters the figure of a subject as an independent, autonomous agent (superman) and reduces him/her into a dependent object, equal in status to water and a bed which are basic items albeit necessary for survival. A confrontation with mortality thus leads to Erin perceiving death as a limitation to enjoyment, an error associated with fragility, weakness, and one that shatters the belief in the existence of a subject as independent. Likewise, the strength of the meaning of her life is reduced as she perceives her life as one in a deteriorating, 
survival mode, without the superman who infinitely provided for her. In a way she too perceived herself transformed from a subject to an object, one that yearns, more than ever, to be a subject and retain that which was lost. Paradoxically, death in the place of real acts as a limit to life and meaning inherent in a constructed reality, but death is at the same time that which induces and drives a quest for meaning, a demand and an appeal towards the Other insofar as the reminder threatens to dissolve the being of her subjectivity. 


\section{(4) Conclusion}

The above analysis has attempted to trace through Lacanian Discourse Analysis the construction of the idea of death by a focus on Lacan's three, intertwined registers that form subjectivity; the symbolic, the imaginary and the real (SIR). To briefly sum up the analysis of the narratives, Julia is confronted with the real deteriorating body as her mother is diagnosed with breast cancer, whereby she comes up against her own imagined threat of death through a (mis-)recognition with the mother. The (mis-)recognition and an identification with breast cancer allows Julia to feel a sense of mastery by attempting to reduce the real to the imaginary and symbolic wherein the real can be imagined to be controlled with reason, knowledge and a focus on behaviour. As this process fails, the real disrupts fantasy in which death is seen as a foreign, random, anxiety-provoking thing that would dissolve individuality. The second participant, Kate, comes up against the radical otherness inherent in the symbolic order through a failure to symbolise her rape, as a way to prevent the second rape from happening to her friend. This leads to a drive for responsibility and leads to her perceived position/punishment as symbolically dead. The real disintegrates the phantasmic world and prevents any secure, stable feelings therein which causes anxiety and an impossible position, as split between a drive for responsibility and a desire for a coherent symbolic position. Lastly, Erin experienced the death of her father and of a childhood friend that resulted in an unbearable new symbolic position and in a perceived forever lost and unattainable love. This resulted in an attempt to overwrite the real with the imaginary-symbolic as a way to rectify what had been prohibited, but ironically the imaginary-real returned as an ubiquitous, anxiety-provoking presence and a remainder of the trauma.

Firstly, what the three analysed narratives have brought to light is the impossibility of making sense of death. More precisely, it is the dealing with the real in relation to the symbolic and imaginary that forms a relationship to death. Cancer, rape and death are all encounters with the real; underneath these words lies a radical otherness, something standing in opposition to a stable, integrated identity, that is not accessible in an immediate reality as it fails to be absorbed by language. The decomposition of a body, the deterioration and intrusion upon a human body by another body all point to a place beyond the symbolic realm, beyond our grasp. In this way, death can only be cloaked in imaginary and symbolic clothes in coming to be represented in reality - it is not conceivable without the knotting together of the three registers. Death, therefore, cannot be captured in the 
relational system of the symbolic but is something (real) that resists incorporation into collective norms, reason or knowledge.

Secondly, the analysis illustrates that the interaction of the SIR comes to determine the perceptions on death. The imaginary allows one to ignore mortality in a quest for immortality as a way to gain an illusory feeling of mastery (over death), in line with Julia and Erin's narratives. The impossibility of death means that it can emerge in various nuances in reality, for example it can be seen as a prohibition on enjoyment, an error or flaw of human life, or a necessary position for punishment. It has been seen how ignoring death results in an even larger presence of the unknown, object $a$, as occupying a mysterious, horrifying presence in fantasy. The nuance of death thus bears immense significance in feelings of anxiety and is an important point of scrutiny.

Moreover, this project reveals how death and life are inextricably bound up insofar as representations are detached from a subject's real being and can function autonomously. When the safety net of the imaginary falls, one comes up against the lack inherent in the symbolic, and thus, comes up against mortality: the fragile, fleeting groundless existence and ultimately a nothingness that represents a subject through language, which is what all of them encounter. This is what is involved in a symbolic death; an exclusion from society, from the Other, which can be a horrifying experience and one not necessarily coterminous with a physical death.

Finally, this project has delineated the suspenseful relationship between a constructed reality and the real, i.e. between life and death that underlies the interdependent existence of a subject. Hegel's master-slave dialectic mentioned in the beginning that inspired Lacan's conceptualisation of subjectivity (see page 10), has demonstrated throughout the analysis that: the subject is in a position of a slave in relation to the Other, as he/she only gains an existence from an acknowledgment emanating from something other than himself/herself, language, in exchange for performing the work of a signifying chain. Translating this to the relationship between a subject and death as a master, a subject can only exist against the knowledge/background of non-existence. The paradoxical nature of the real, and death (to the extent to which they can be coterminous), is that it threatens to dissolve that which it gives rise to. This tension between life and death, between being and nothingness, while producing a split, lacking subject stuck in an impossible position, propels desire in that the threat of dissolution drives a construction for meaning and a 
coherent identity: a desire to (re)find meaning in a new symbolic position (Erin), a desire to find answers around an illness as a way to avoid it (Julia), or a desire for a place in society from which meaning can be assembled (Kate).

Overall, Western society's depiction of death, wherein death is in opposition to life, entails the belief of a possibility of separating the two and overwriting death with knowledge. I have argued in this project that such a position is impossible. Language carries with it the dimension of death and in this way, life and death become inextricably bound up. As long as language acts as a mediator between a subject and death, death escapes any reason, logic and finite knowledge. 


\section{(5) References}

Bendle, M. F. (2001). Death, the Abyss and the Real. Psychoanalytic Studies, 3(2), 223-236.

Blumenstein, E., \& Ensslin, F. (2007). Between two deaths. Hatje Cantz Pub, pp. 26-39.

Borch-Jacobsen, M. (1991). Lacan: The absolute master. Stanford, Calif: Stanford University Press.

Critchley, S. (2004). Very little... almost nothing: death, philosophy and literature. Routledge.

Dolar, M. (2003). "I shall be with you on your wedding-night": Lacan and the uncanny. Jacques Lacan, 63-81.

Evans, D. (1996). An Introductory Dictionary of Lacanian Psychoanalysis. London: Routledge.

Eyers, T. (2012). Lacan and the concept of the 'real'. Houndsmills, Basingstoke, Hampshire: Palgrave Macmillan.

Fink, B. (1995). The Lacanian subject: Between language and jouissance.

Princeton, N.J: Princeton University Press.

Fink, B. (2004). Lacan to the letter: Reading Écrits closely. Minneapolis, MN: University of Minnesota Press.

Freud, S. (1957) 'Thoughts for the times on war and death', in The Standard Edition of the Complete Psychological Works of Sigmund Freud, Volume XIV (1914-1916): On the History of the Psycho-Analytic Movement, Papers on Metapsychology and Other Works, pp. 273-300.

Frosh, S., Phoenix, A., \& Pattman, R. (2003). Taking a stand: Using psychoanalysis to explore the positioning of subjects in discourse. British Journal of Social Psychology, 42(1), 39-53.

Frosh, S. (2014) 'Disintegrating narrative research with Lacan', in Parker, I., \& Pavón-

Cuéllar, D (eds.), Lacan, Discourse, Event: New Psychoanalytic Approaches to Textual Indeterminacy. Routledge, pp. 17-27.

Hegel, G. W. F. (1980). The phenomenology of mind. Trans. B. Baillie, J.B. New York: Humanities Press.

Homer, S. (2005). Jacques Lacan. London: Routledge.

Hook, D. (2008). Absolute Other: Lacan's Big Other' as Adjunct to Critical Social Psychological Analysis?. Social and Personality Psychology Compass, 2,(1), 51-73.

Kirshner, L. A. (2005). Rethinking desire: The objet petit a in Lacanian theory. Journal of the American Psychoanalytic Association, 53(1), 83-102.

Kojéve, A. (1969). Introduction to the Reading of Hegel. Ithaca: Cornell University Press.

Lacan, J. (1988). The Seminar of Jacques Lacan, Book II: The Ego in Freud's Theory and in the Technique of Psychoanalysis, 1954-1955. Trans. B. Tomaselli, S. WW Norton \& Co.

Lacan, J. (1992). The Ethics of Psychoanalysis: The Seminar of Jacques Lacan, 1959-1960, Seminar VII, Miller, Trans. B. Porter, D.

Lacan, J. (2002/2006). Écrits, The First Complete Edition in English, Trans. B. Fink

Long, A. A., \& Sedley, D. N. (1987). The Hellenistic philosophers. Cambridge, Cambridgeshire: Cambridge University Press.

Loose, R. (2002). The subject of addiction: Psychoanalysis and the administration of enjoyment. London: Karnac.

McGowan, T. (2004). The end of dissatisfaction?: Jacques Lacan and the emerging society of enjoyment. Albany: State University of New York Press. 
Neill, C. (2011). Lacanian ethics and the assumption of subjectivity. Houndmills, Basingstoke, Hampshire: Palgrave Macmillan.

Neill, C. (2013). Breaking the text: An introduction to Lacanian discourse analysis. Theory \& Psychology, 23(3), 334-350.

Parker, I. (2005a). Lacanian discourse analysis in psychology: seven theoretical elements. Theory and psychology, 2005, 15, 163-182.

Parker, I. (2005b). Qualitative Psychology: Introducing Radical Research. Berkshire, UK: Open University Press

Pavón Cuéllar, (2010). From the conscious interior to an exterior unconscious: Lacan, discourse analysis and social psychology. Karnac Books.

Pavón Cuéllar, D. (2014) 'From the word to the event: limits, possibilities and challenged of Lacanian Discourse Analysis', in Parker, I., \& Pavón-Cuéllar, D (Eds.), Lacan, Discourse, Event: New Psychoanalytic Approaches to Textual Indeterminacy. Routledge.

Pavón Cuéllar, D. \& Parker, I. (2014) 'Introduction: Lacanian theory, discourse analysis and the question of the 'event", in Parker, I., \& Pavón-Cuéllar, D (Eds.), Lacan, Discourse, Event: New Psychoanalytic Approaches to Textual Indeterminacy. Routledge.

Ragland, E. (1995). Essays on the Pleasures of Death. New York: Routledge.

Razinsky, L. (2013). Freud, psychoanalysis and death. Cambridge: Cambridge University Press.

Ruti, M. (2012). The singularity of being: Lacan and the immortal within. New York: Fordham University Press.

Salecl, R. (2000). Love and sexual difference: double partners in men and women. Duke University Press.

Salecl, R. (2004). On anxiety. London: Routledge.

Verhaeghe, P. (1995). From impossibility to inability: Lacan's theory on the four discourses'. The Letter: Lacanian Perspectives on Psychoanalysis, 3, 91-108.

Wrathall, M. A. (2006). How to read Heidegger. New York: W.W. Norton.

Young, S, L. (2014) 'Becoming other to oneself: misreading the researcher through Lacanian Discourse Analysis', in Parker, I., \& Pavón-Cuéllar, D (Eds.), Lacan, Discourse, Event: New Psychoanalytic Approaches to Textual Indeterminacy. Routledge, pp. 279-291.

Žižek, S. (1989). The sublime object of ideology. London: Verso.

Žižek, S. (1991). Looking awry: An introduction to Jacques Lacan through popular culture. Cambridge, Mass: MIT Press.

Žižek, S. (2006). How to read Lacan. London: Granta Books 
(6) Appendices

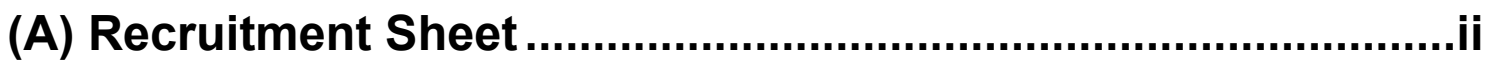

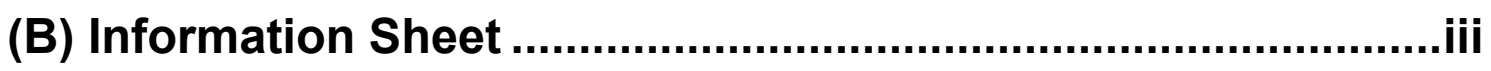
(C) Consent Form ……............................................................

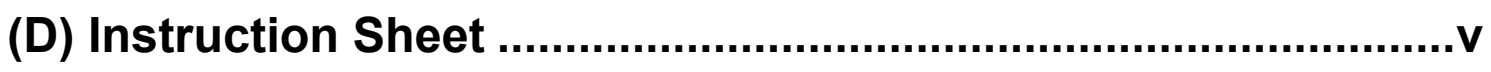
(E) Debriefing Sheet .................................................................... 


\section{(A) Recruitment Sheet}

\section{Edinburgh Napier}

UNIVERSITY

\section{Looking for volunteers}

My name is Amanda Diserholt and I am an undergraduate student in Psychology at Edinburgh Napier University. As part of my degree course, I am undertaking a research project for my Honours dissertation. This study will qualitatively explore the idea of death in relation to culture and language from a psychoanalytic perspective. I am looking for volunteers to participate in the project. There are no criteria (e.g. age, gender and health) for being excluded or included everyone is welcome to take part.

\section{Procedure}

Taking part in the study means that you will be asked to participate in a short writing task, taking place at a location of your choice, for example at home, at a time that suits you. You will be asked to write down two events that you feel have significantly changed your life. You should only participate if you feel comfortable with this and willing to share these experiences. The answer should be typed on a computer and the whole procedure should take around 30 minutes.

If you agree to take part, I will email you with more information about taking part and everything will be done through email. If you are interested in taking part in this research study, please contact me by email at the following address: $40064497 @$ live.napier.ac.uk

If you are unsure about taking part and/or have any questions, do not hesitate to get in touch!

Thank you very much in anticipation.

Kind regards,

Amanda Diserholt 


\title{
A Qualitative Exploration of Death \& Desire
}

My name is Amanda Diserholt and I am an undergraduate student from the School of Life, Sport \& Social Sciences at Edinburgh Napier University. As part of my degree course, I am undertaking a research project for my Honours dissertation. This study will qualitatively explore the concept of death in relation to language and culture from a psychoanalytic perspective. The findings of the project will be valuable because they will contribute to research into psychoanalysis and discourse analysis.

I am looking for volunteers to participate in the project. There are no criteria (e.g. age, gender and health) for being excluded or included - everyone is welcome to take part.

\section{Procedure}

If you agree to participate in the study, you will be asked to participate in a writing task, taking place at a location of your choice, for example at home, at a time that suits you. You will be asked to write down two events that you feel have significantly changed your life. The answer should be typed up on the computer and emailed to me. The whole procedure should take no longer than 40 minutes. You will be free to withdraw from the study at any stage without giving a reason and without any penalty. To ensure that enough data is gathered for the project, I will recruit five participants in total, and your data from this writing task may not be used for the final report.

All data will be anonymised as much as possible. Your name will be replaced with a pseudonym, and it will not be possible for you to be identified in any reporting of the data gathered. All data collected will be kept on a password-protected computer to which only my supervisor and I will have access. These will be kept till the end of the project, following which all data will be destroyed. The results may be published in a journal or presented at a conference.

If you have any further questions, you are welcome to contact me or my project supervisor:

\author{
Amanda Diserholt \\ School of Life, Sport \& Social Sciences \\ Edinburgh Napier University \\ Sighthill Campus \\ Sighthill Court \\ Edinburgh EH11 4BN
}

Email: 40064497@live.napier.ac.uk

\author{
Dr Calum Neill \\ School of Life, Sport \& Social Sciences \\ Edinburgh Napier University \\ Sighthill Campus \\ Sighthill Court \\ Edinburgh EH11 4BN
}

Email: c.neill@napier.ac.uk Tel: (0131) 4556169

If you would like to contact an independent person, who knows about this project but is not involved in it, you are welcome to contact Dr Barbara Neades, Convenor of Faculty Research Ethics Approval Group. Her contact details are given below:

\author{
Dr Barbara Neades; Senior Lecturer; \\ Faculty of Health, Life \& Social Sciences; Edinburgh Napier University \\ Sighthill Campus \\ Sighthill Court \\ Edinburgh EH11 4BN \\ (tel: (0131) 455 5315, email: b.neades@napier.ac.uk)
}

If you have read and understood this information sheet, any questions you had have been answered, and you would like to be a participant in the study, please now see the consent form. 


\section{(C) Consent Form}

\section{Edinburgh Napier}

\section{A Qualitative Exploration of Death and Desire}

I have read and understood the information sheet and this consent form. I have had an opportunity to ask questions about my participation.

I understand that I am under no obligation to take part in this study.

I understand that I have the right to withdraw from this study at any stage without giving any reason.

I agree to participate in this study.

Name of participant:

Signature of participant:

Signature of researcher:

Date:

\section{Contact details of the researcher}

Name of researcher: Amanda Diserholt

Address: Undergraduate Student, Psychology

School of Life, Sport \& Social Sciences

Edinburgh Napier University

Sighthill Campus

Sighthill Court

EH11 4BN

Email: $\quad$ 40064497@live.napier.ac.uk

Independent advisor: Dr Barbara Neades; Senior Lecturer;

Address: $\quad$ Faculty of Health, Life \& Social Sciences; Edinburgh Napier University Sighthill Campus

Sighthill Court

Edinburgh EH11 4BN

Tel:

(0131) 4555315

Email: $\quad$ b.neades@napier.ac.uk) 


\section{(D) Instruction Sheet}

\section{Edinburgh Napier}

Recall two events in your past that have significantly these events and include answers to the following:

- In what ways did they change your life?

- To what extent do you feel these events have been shaped by your culture?

Write your answer on a computer in this document and use as many pages as needed. When you are finished, save this document and email it back to me on the following address:

40064497@live.napier.ac.uk 


\section{(E) Debriefing Sheet}

\section{A Qualitative Exploration of Death and Desire}

Thank you very much for participating in this study - it is extremely helpful for my research. I will look at your writing to attempt to understand the role of language and culture in shaping life experiences by looking at your writing from a psychoanalytic perspective and analyzing it through the framework of a 'Lacanian Discourse Analysis'.

Your contribution to this research is valuable for theoretical reasons. It will highlight the importance of language and culture in shaping a person's relationship to life and death. We can deal with the knowledge of our inevitable deaths in numerous of ways, and psychoanalytic theory offers rich explanations of this and suggests that the repression of the knowledge of our deaths influences our acts and thoughts. The concept of death in this project is adopted from the perspective of psychoanalyst Jaqcues Lacan, who offers an in-depth explanation of how death is highly interlinked with life and thus life wishes. You were therefore asked to write down life-changing events. If you would like to find out more about this topic I can give you some recommendations for reading.

You are free to withdraw your contributions from this research without giving any reason and without penalty. To do this, please contact me on the details below. In addition, if you have any questions later on or would like to read the finished project, please contact my supervisor or myself.

\section{Amanda Diserholt}

School of Life, Sport \& Social Sciences

Edinburgh Napier University

Sighthill Campus

Sighthill Court

Edinburgh EH11 4BN

Email: 40064497@live.napier.ac.uk

\author{
Dr Calum Neill \\ School of Life, Sport \& Social Sciences \\ Edinburgh Napier University \\ Sighthill Campus \\ Sighthill Court \\ Edinburgh EH11 4BN
}

Email: c.neill@napier.ac.uk

Tel: (0131) 4556169

If you would like to contact an independent person, who knows about this project but is not involved in it, you are welcome to contact Dr Barbara Neades, Convenor of Faculty Research Ethics Approval Group. Her contact details are given below:

Dr Barbara Neades; Senior Lecturer;

Faculty of Health, Life \& Social Sciences; Edinburgh Napier University

Sighthill Campus

Sighthill Court

Edinburgh EH11 4BN

(tel: (0131) 455 5315, email: b.neades@napier.ac.uk)

If you should feel distressed after participating in this study and would like to talk to someone, you can contact the following organizations:

Samaritans: 08457909090

Breathing Space: 0800838587

Health in Mind: 01312258508 